\title{
Creating Environments for Critical Thinking: Building Upon Multiple Choice Problems in Electrical Engineering Education
}

\section{Dr. Saharnaz Baghdadchi, University of California, San Diego}

Saharnaz Baghdadchi is an Assistant Teaching Professor at UC San Diego. She is interested in scholarly teaching and uses active learning techniques to help students achieve expert-like level of thinking. She guides students in bridging the gap between facts and usable knowledge to solve complex engineering problems.

\section{Zoe Nemerever, University of California San Diego}

Zoe Nemerever is a $\mathrm{PhD}$ candidate in the Department of Political Science at the University of California San Diego.

Mr. Paul Andreas Hadjipieris, University of California, San Diego

Paul Hadjipieris is an instructional designer at the University of California San Diego. He holds an MA, in history from Edinboro University of Pennsylvania. His research agenda is on emerging educational technologies and their application to the classroom. He is deeply involved in SoTL research at the University of California San Diego and currently working with faculty on course design and manuscript construction.

Dr. Sheena Ghanbari Serslev

Dr. Carolyn L. Sandoval, University of California, San Diego

Dr. Sandoval is the Associate Director of the Teaching + Learning Commons at the University of California, San Diego. She earned a PhD in Adult Education-Human Resource Development. Her research interests include adult learning and development, faculty development, qualitative methods of inquiry, and social justice education. 


\title{
Creating Environments for Critical Thinking in Electrical and Computer Engineering Education
}

\begin{abstract}
Fostering critical thinking is an important part of any course design in Engineering education. It needs deliberate attention, and the implemented interventions must be routinely monitored and assessed. The need for analysis skills is prominent in a wide range of lower division and upper division engineering courses. One course in particular that requires strong critical thinking ability is the analog circuit course in which students learn about nonlinear circuit elements such as diodes, bipolar junction transistors, field effect transistors and their applications in designing functional circuits. Electrical and Computer Engineering students taking the course are required to make logical assumptions about the operation of these circuit elements and justify their assumptions based on the calculated results. Students struggle with analyzing the networks with a combination of these nonlinear circuit elements and relating them to the design of functional circuits as it demands a higher level of understanding.
\end{abstract}

In this paper, we present a study of the impact on student learning when integrating take-home tests, peer instruction, pre-lecture videos, and guided quizzes in a lower division analog circuits course. The goal of these interventions was to improve critical thinking, essential for all engineering students, and to improve student mastery of course learning outcomes, among electrical and computer engineering students. This study ran through the Winter and Spring quarters in 2018. Survey data were collected at three points throughout both quarters to monitor the students' perception of the interventions and the effectiveness of the techniques. In addition to the survey data, students' responses to the challenging and authentic problems on the midterm and final exams and their grades were used to assess the effectiveness of the implemented techniques in improving critical thinking skills and to make changes to the design of the course at the end of the first offering of the redesigned course.

According to our results, $86 \%$ of the students found the take-home tests effective in developing a profound understanding of the course topics in the second quarter. Compared to the student responses in the first quarter in which $65 \%$ of the participants mentioned that to be able to solve exam problems, they must have seen a similar circuit beforehand, in the second quarter $69 \%$ agreed that they can solve a circuit problem without seeing a similar problem beforehand. The survey findings, alongside an analysis of student exam grades, provide strong evidence that the implemented interventions have supported the development of problem-solving and critical thinking skills among Electrical and Computer Engineering students.

\section{Introduction}

To support discoveries that advance society, our university promotes the practice of dedication to equipping students with multidisciplinary tools. Faculty in the Engineering school at UC San Diego, a large public research institution, strive to develop strategies to cultivate critical thinking skills in Engineering students. This study was conducted in Components and Circuits Lab, a core Electrical Engineering course, to test the effect of peer instruction, take-home tests, and prelecture videos on improving students' critical thinking and mastery of course learning outcomes. 
The course level learning outcomes require students to analyze unique circuit problems that were not practiced in the class, and design functional circuits using the methods of analyzing circuits learned in the class.

In Components and Circuits Lab (ECE 65), students learn about linear and non-linear circuit components such as operational amplifiers (op-amps), diodes, and transistors. In addition to analyzing the operation of these circuit elements, students are expected to use the acquired primary knowledge to design functional circuits according to the specified constraints. For example, after learning about the op-amps and how to analyze op-amp circuits, they are asked to design weighted summer circuits or op-amp circuits for removing the noise added to the signal. As another example, after they learned the basics of the operation of bipolar junction transistors and their applications as amplifiers, they are asked to design amplifiers for the desired gain and output voltage swing.

To accomplish the design-related tasks in the class, students need to achieve a higher level of learning and reach a mastery level in analyzing the related circuits. In the traditional lecture style of teaching previously used in this course, many students could not achieve the instructors' desired mastery level and struggled with solving the synthesis-level problems. To address this issue, the following interventions were implemented in the course offered in the Winter and Spring quarters of 2018.

In Winter 2018, the course instructor added a series of multiple choice iClicker questions to each lecture. Students were asked to solve the problems individually and then discuss the problems and explain their solutions to their peers. Four homework assignments were also added to the course to give students more practice with the problems and to provide additional checkpoints for the instructor and students to assess understanding. Similar to past quarters, one midterm and one final exam were also used to assess learning. Based on analyses of student feedback in the surveys and their midterm and final exam grades, the instructor added new components to the Components and Circuits Lab offered in the Spring quarter and revised the structure of the class further. One newly added component was two optional take-home tests. These tests had a problem related to the course topics, but solving the problem required a more in-depth knowledge of the topics. To answer the questions in the test, students had to analyze the operation of the challenging circuits. They were required to discuss the effect of changing the values of the circuit components or the amplitude of the current and voltage sources on the operation of the circuits, and finally design circuits to achieve the desired outcomes. Another added component was a series of pre-lecture video screencasts of the instructor teaching parts of each lecture, and a multiple-choice question at the end to check for understanding. Students were highly encouraged to complete the take-home tests, and watch the pre-lecture videos and answer their related questions before coming to class.

Similar to the Winter quarter, in the Spring offering of the course, iClicker and discussion questions were integrated into the lectures, and a midterm and a final exam were used for assessment. To further adjust the course structure, the instructor replaced the homework assignments used in the Winter quarter with the weekly quizzes in the Spring quarter. The type of circuit problems in the weekly quizzes and their level of difficulty were similar to the ones in the previously used homework assignments. 
In this study, the test and control groups were composed of ECE 65 students in the Spring quarters who opted out of taking the take-home tests and watching the pre-lecture videos, and students who took the tests and/or watched the videos. The final exam grades and the survey results were used as the assessment tools for analyzing the effectiveness of the new components added to the course and the revised structure of the course in the Spring quarter. Additionally, instructor reflections on the process of revising the course from Winter to Spring quarter are provided in this paper.

\section{Literature Review}

There has been an ongoing effort to improve engineering instruction and create learning experiences that echo practical skill-sets in the field (Felder et al., 2000). Accordingly, there has been a breadth of research that examines various teaching methodologies in the discipline. To frame this research, an overview of the importance of critical thinking in engineering education is presented alongside a review of different assessment and blended instructional methods that influence student learning.

\section{Critical Thinking in Engineering Education}

Critical thinking has been cited as a hallmark of a university education that is an integral component of intellectual activity and a trait of life-long learners (Ahern et al., 2012; Siegel, 1980; Tsui, 2016). It is an educational ideal that is valued across disciplines and has been repeatedly noted as a desirable skill-set for students entering the workforce. Most broadly, critical thinking is "reflective and reasonable thinking that is focused on what to believe or do" (Ennis, 1985, p.45). Critical thinking in an engineering context has been described as the ability to perform a task, question and reflect upon it while grounding their reflection in reality. It is important to note the critical thinking as a dynamic concept in engineering that requires students to navigate between empirical and abstract knowledge (Ahern, et al., 2012).

Collaboration is often closely linked with critical thinking. This is not surprising given the teambased nature of most engineering professions and the inclusion of communication and teamwork as an explicit goal in the accreditation of engineering programs (Woods, et al., 2000).

Furthermore, Mills and Treagust (2003) posit that traditional "chalk and talk" pedagogies remain prevalent in engineering education despite the mounting evidence in support for collaborative approaches like problem-based or project-based learning. In thinking about creating classroom environments that encourage collaboration and critical thinking, types of assessments should be carefully considered.

\section{Using Assessments to Promote Learning}

How instructors measure student success influences course outcomes. Course assessments are a key tenant of course design and determine the metrics of measurement for student proficiency in course learning outcomes (Wiggens \& McTighe, 1995). Traditional assessments, like multiple choice tests and problem-sets, are prevalent in engineering education (Claris \& Riley, 2012; Nicol, 2007). While the literature includes some benefits of these types of assessments there is a growing body of research examining alternate means assessment that is more reflective of the 
profession. Multiple choice assessments, specifically, are a means of accommodating for large classroom size and allowing for rapid student feedback (Nicol, 2007). Claris and Riley (2012) suggest that these types of assessments are not reflective of the discipline and imply that Engineers work primarily with multiple choice questions and problem-sets; these assessments lack the student reflections and critical questions necessary to engage more deeply in the subject matter.

To move towards a curriculum that places a higher value on critical thinking and collaborative skill-sets, assessments should incorporate opportunities for students to mimic applied engineering situations (Bordogna, 1993; Springer et al., 1999; Singer \& Smith, 2013). This is exemplified with the curriculum redesign at Maastricht University where a traditional lecture model was restructured to integrate courses with case studies and projects. This approach integrated group-work that allowed students additional opportunities to practice and apply the concepts presented in the course (Perrenet, 2000). In another example of engineering curriculum analysis, Siller (2001) shared sample course exercises designed to measure critical thinking. Rather than presenting problem-sets or exams, the activities have multiple steps and opportunity for reflection and articulating decision-making.

In addition to the emphasis on critical thinking skills in engineering education, there is also a movement to push towards an active learning approach (Baghdadchi et al., 2018; Chi, 2009; Freeman, 2014). Through active learning, students acquire knowledge and skills through practice and reflection, rather than passively absorbing the material (Felder, et al., 2000). A meta-analysis of active learning literature in engineering education shows that, while different studies vary in strength, there is a clear connection to increased student engagement when an instructor implements an active approach, and multiple studies show that students remember more content from a lecture if it includes brief activities. Furthermore, the literature presents a case for creating classrooms that promote collaboration and cooperation rather than competition and achievement (Prince, et al., 2004). Positive effects of group learning unrelated to the material include high self-esteem, forming interpersonal relationships with classmates, creating a sense of social support in the classroom, and positive attitudes towards learning in general (Prince 2004; Springer et al., 1999).

An active learning classroom lends itself to hybrid and blended instruction. Blended learning replaces some aspects of face-to-face teaching by removing some of the lecture content to online videos or other mediums, through these mediums, students are expected to acquire knowledge before class and have an opportunity to practice and apply problems during the allotted class time (Clark, et al., 2018). While this methodology does not imply immediate student learning gains, research suggests there are positive student learning implications in blended engineering classrooms (Dziubian \& Moskal, 2001; Jensen et al., 2015).

While there has been some research on the benefits of peer instruction there have been limited studies that specifically examine peer instruction and group examinations in engineering coursework. Peer instruction has proven to be a strong starting point for students to articulate their own perceptions of how they see a problem and evaluate a solution, this type of group work encourages students to apply metacognitive skills (Ahern et al., 2012; Siller, 2001; Perrenet, Bouhuijs, \& Smits, 2000). In Baghdadchi et al., (2018) engineering students stated that the 
integration of peer instruction and collaborative guided quizzes were helpful towards their learning.

Building upon the importance of critical thinking and active learning in engineering education this study aims to fill a void in the current literature and share the impact of an instructor integrating pre-class videos, peer instruction, and take-home tests in an undergraduate Electrical Engineering course.

\section{Setting}

This study was conducted at UC San Diego, a large public research-intensive university in the United States with an approved IRB project. The course, Components and Circuits Lab, was offered in the Winter and Spring quarters of 2018. The course was taught in three weekly 50minute class sessions. The same instructor taught the course in both quarters covering the same topics. Both quarters had approximately 120 students enrolled. Four students from the Winter quarter retook the course in the Spring. Surveys were completed by 50 and 78 students in the Winter and Spring quarters, respectively. Table 1 shows the breakdown of students by gender and year in the program.

Table 1. The number of students and their college year.

\begin{tabular}{|l|l|l|l|l|l|l|l|}
\hline Quarter & Total & Female & Male & 1st year & 2nd year & 3rd year & 4th+ year \\
\hline Winter & 117 & 15 & 112 & 0 & 13 & 68 & 36 \\
\hline Spring & 122 & 18 & 104 & 0 & 17 & 69 & 36 \\
\hline
\end{tabular}

\section{Course Design}

In the Winter quarter, the instructor lectured for about two-thirds of the class time and the rest of the time was spent on peer instruction. Peer instruction was implemented through multiple choice and discussion questions. Students answered multiple-choice questions in class using iClickers. Multiple-choice questions provided the students with frequent opportunities to test themselves, without monopolizing classroom time. For more involved peer-instruction opportunities, students discussed open-ended questions in groups of 3-4 students. Open-ended discussion questions encouraged students to generate solutions to the problem instead of guessing the answer or testing the given answer choices. The practice of answering open-ended questions was important preparation for the types of questions students would later be required to answer on exams.

In the Spring quarter, the instructor continued using multiple choice and discussion questions in the lecture sessions. The instructor added a series of pre-lecture videos to the course, optional take-home tests, and rebranded the homework assignments as weekly quizzes.

The pre-lecture videos were 10-minute screencasts that the instructor recorded of herself teaching about half of the topics in each lecture. Students answered a single multiple-choice 
question at the end of each pre-lecture video. To encourage students to watch the videos before coming to the class, the instructor offered one percentage point extra credit to the final course grade for students who watched all of the lecture videos and answered all of the post-video multiple choice questions correctly. The students who did not watch the pre-lecture videos or answer the post-video questions did not lose any points in their total course grade.

The goal of the pre-lecture videos was to increase the amount of class time available for peer instruction, including the multiple choice and discussion questions. During class meetings, the instructor spent about one-third of the time lecturing and the other two-thirds of the class were spent on multiple choice and discussion questions. This is half the amount of time spent lecturing during the Winter quarter.

Table 2: Course Components

\begin{tabular}{|l|l|}
\hline Winter Quarter & Spring Quarter \\
\hline iClickers and class discussions & iClickers and class discussions \\
\hline Homework assignments & Weekly quizzes \\
\hline Midterm & Midterm \\
\hline Final & Final \\
\hline Labs & Labs \\
\hline & $\begin{array}{l}\text { Pre-lecture videos and reading quizzes prior } \\
\text { to each class }\end{array}$ \\
\hline & $\begin{array}{l}2 \text { optional take-home tests, could be done in } \\
\text { groups }\end{array}$ \\
\hline
\end{tabular}

In addition to the pre-lecture videos, two optional take-home tests were added to the course in the Spring quarter. The instructor strongly encouraged the students to complete the take-home tests. Each test was worth $10 \%$ of the total course grade. If students chose not to complete the take-home tests, the total grade break down was distributed over the midterm $(5 \%)$ and the final exam $(15 \%)$.

The first test occurred before the midterm, and the second test occurred between the midterm and final exams. On average, students had ten days to complete the take-home tests. The instructor encouraged students to work on the take-home tests with their peers. Students were asked to prepare a 5-10 minute screencast explaining their solution and submit it along with their written solution. This was to reinforce learning by explaining and to maintain the academic integrity of the tests. The tests included challenging circuit problems that required a mastery level of understanding of the topics. They were intended to refine students' critical thinking skills by encouraging them to experiment with different problem-solving approaches to design circuits that satisfy certain sets of constraints. 
Finally, the instructor transformed the Winter quarter homework assignments into weekly quizzes for the Spring quarter. The homework assignments and weekly quizzes were similar in content. In addition, the course in both quarters had weekly lab sections that were scheduled for three hours per week. The lab assignment did not change after the Winter quarter.

\section{Student Selection into Treatment Conditions}

Table 3 shows the number of students that selected into each treatment group during Spring quarter. The majority of students elected to complete both the optional pre-lecture videos with questions and the optional take-home tests. Over twice as many students completed just the takehome tests than students who completed only the pre-lecture videos and questions. Slightly over one-tenth of the class chose to not participate in either of the optional activities.

Table 3: Treatment Groups

\begin{tabular}{|l|c|c|}
\hline & Watched pre-lecture videos & Did not watch pre-lecture videos \\
\hline Optional take-home tests & $\begin{array}{c}\text { Group 1: } \\
70 \text { students (57\%) }\end{array}$ & $\begin{array}{c}\text { Group 2: } \\
28 \text { students (23\%) }\end{array}$ \\
\hline No optional take-home test & $\begin{array}{c}\text { Group 3: } \\
11 \text { students (9\%) }\end{array}$ & $\begin{array}{c}\text { Group 4: } \\
13 \text { students (11\%) }\end{array}$ \\
\hline
\end{tabular}

Table 4 shows the year and gender balance of students, and whether or not they were enrolled in the Electrical and Computer Engineering major for each of the four treatment groups. Female students were slightly more likely than male students to take advantage of both of the optional learning activities. There was no notable pattern of treatment uptake among the different years in the class. The other majors include Chemical Engineering, Cognitive Science, Computer and Science Engineering, Mathematics, Physics, Bioengineering, Structural Engineering, Undeclared Physical Sciences, and Undeclared.

Table 4: Balance Tables of Participants (Spring Quarter only)

\begin{tabular}{|l|c|c|c|c|c|}
\hline & Class & Group 1 & Group 2 & Group 3 & Group 4 \\
\hline Sophomore & $14 \%$ & $13 \%$ & $21 \%$ & $0 \%$ & $15 \%$ \\
\hline Junior & $57 \%$ & $56 \%$ & $57 \%$ & $64 \%$ & $54 \%$ \\
\hline Senior & $30 \%$ & $31 \%$ & $21 \%$ & $36 \%$ & $31 \%$ \\
\hline In major & $77 \%$ & $79 \%$ & $75 \%$ & $82 \%$ & $69 \%$ \\
\hline Male & $81 \%$ & $79 \%$ & $85 \%$ & $89 \%$ & $81 \%$ \\
\hline Total & 122 & 70 & 28 & 11 & 13 \\
\hline
\end{tabular}




\section{Results and Discussion}

The effects of the active learning techniques were measured using students' final exam grades. Table 5 shows the average final exam grade, and respective standard deviations, for each of the treatment groups. More detailed information about the distribution of final exam grades for the class as a whole and within each treatment group are shown in Table 6 and Figure 2. The data provides mixed evidence for whether or not the pre-lecture videos had an effect on students' grades. Among students who completed the optional take-home tests, the videos had a positive effect of $8 \%$ on the final exam grades. Among students who did not take the optional take-home test, those who watched the videos actually did slightly worse (one-half percentage point). As predicted, students who completed the take-home tests performed significantly better on the final exam than students who did not complete the take-home tests. The effect of the take-home tests was large (6 - 15 percentage points) and was present regardless of whether students chose to watch the pre-lecture videos.

Table 5: Average Final Exam Grade by Treatment Group (standard deviations in parentheses)

\begin{tabular}{|l|c|c|}
\hline & Watched pre-lecture videos & Did not watch pre-lecture videos \\
\hline Optional take-home tests & Group 1: & Group 2: \\
& $66.2 \%$ & $58.1 \%$ \\
& $(1.9 \%)$ & $(3.1 \%)$ \\
\hline No optional take-home test & Group 3: & Group 4: \\
& $51.5 \%$ & $52 \%$ \\
& $(6.9 \%)$ & $(6 \%)$ \\
\hline
\end{tabular}

Table 6: Spring Quarter Final Exam Summary Statistics by Treatment Group, out of 50 points total

\begin{tabular}{|l|l|l|}
\hline & Mean & Median \\
\hline Group 1 & $66.16 \%$ & $66.5 \%$ \\
\hline Group 2 & $58.14 \%$ & $61.5 \%$ \\
\hline Group 3 & $51.44 \%$ & $52 \%$ \\
\hline Group 4 & $52 \%$ & $62 \%$ \\
\hline Class & $61.48 \%$ & $64 \%$ \\
\hline
\end{tabular}

Figure 1 shows that the largest positive effect on final exam grades came from the interaction of the take-home tests and pre-lecture videos. Further, the group of students who completed both treatment conditions is the only group that is statistically significantly different from the control group (no treatments). This suggests that future classes should incorporate both elements in order to provide students maximum benefit. 


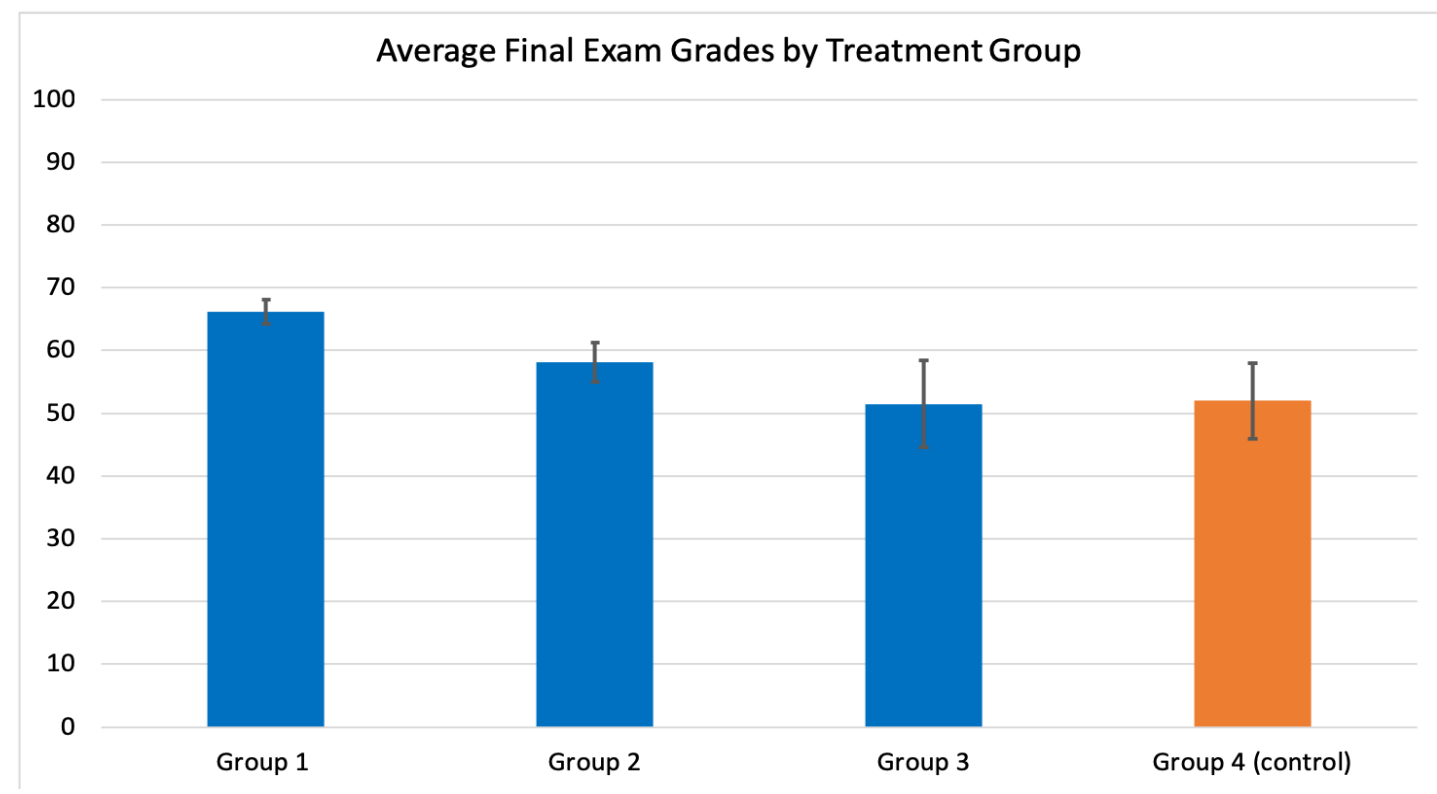

Figure 1: Final exam grades averaged over treatment groups with $95 \%$ confidence intervals.

Figure 2 shows the distribution of final exam grades within each treatment group and for the class. The grades for Group 1 and the class have the most normal distributions, presumably because they have the largest size. Notably, Group 3 has a somewhat uniform distribution, suggesting large variability of exam performance within the group.

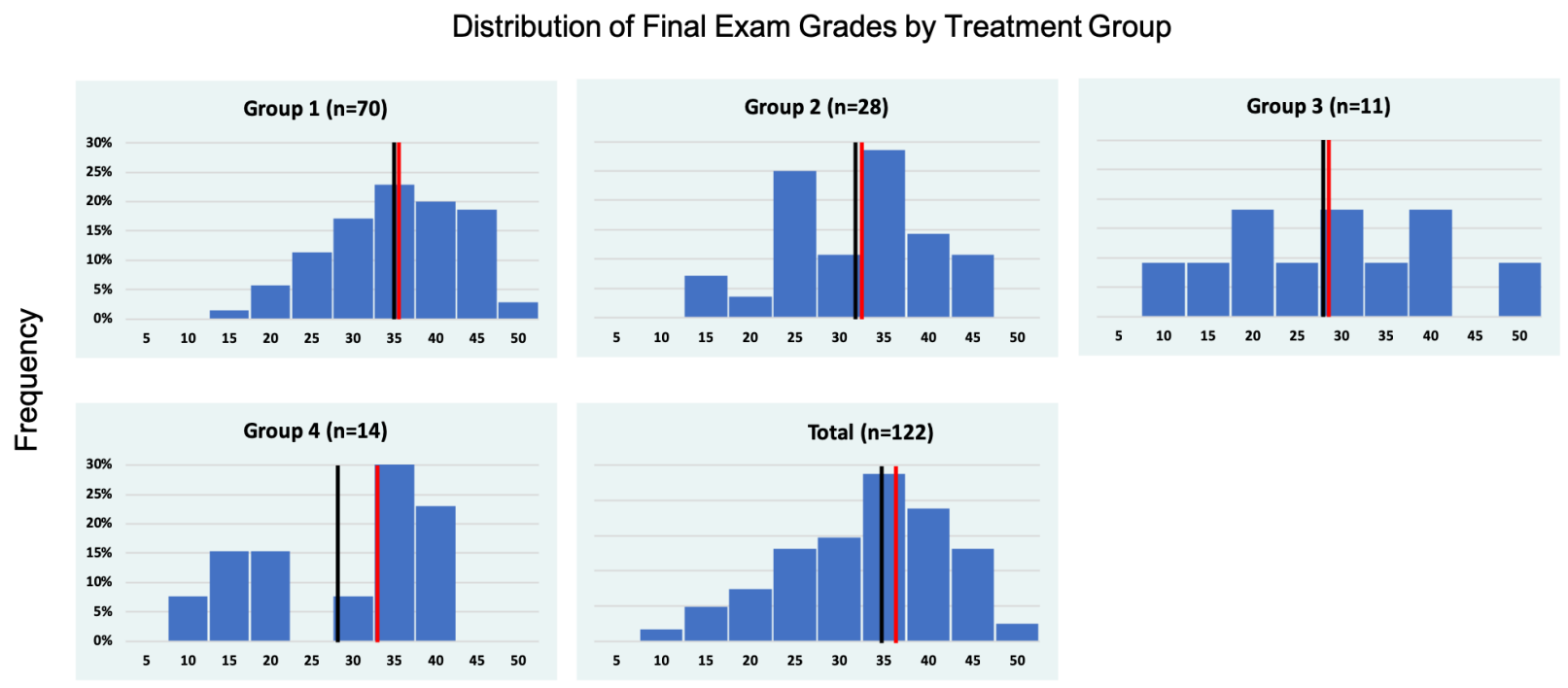

Final exam scores (total score: 50 )

Figure 2. Distribution of Final Exam Grades by Treatment Group. The black and red lines in each graph show the mean and median grades, respectively. The y-axis in each graph shows the percentage of students within each group who scored the grades presented on the $\mathrm{x}$-axis. 
Table 7 shows the average and median cumulative GPA of students in each treatment group. This table also shows the percentage of the students with lower cumulative GPA, relative to the average GPA in the class, who chose the activities in each treatment group. The average cumulative GPA of all students in the class was 3.18 with a median of 3.25 .

As can be seen in Table 7, 45\% of the students who had a below-average GPA, participated in both the take-home tests and watching the pre-lecture videos.

Table 7. The average cumulative GPA of students in each treatment group and distribution of students with below-average GPA in different groups.

\begin{tabular}{|l|l|l|l|l|}
\hline & Group 1 & Group 2 & Group 3 & Group 4 \\
\hline $\begin{array}{l}\text { Average cumulative } \\
\text { GPA (out of 4.0) of the } \\
\text { students in the group }\end{array}$ & 3.29 & 3.08 & 2.88 & 3.06 \\
\hline $\begin{array}{l}\text { Median cumulative } \\
\text { GPA (out of 4.0) }\end{array}$ & 3.36 & 3.17 & 2.76 & 3.18 \\
\hline $\begin{array}{l}\text { Percent of students } \\
\text { with a cumulative GPA } \\
\text { below the class average } \\
\text { in the group }\end{array}$ & $45 \%$ & $28 \%$ & $15 \%$ & $12 \%$ \\
\hline
\end{tabular}

When redesigning this course, two important course level outcomes were the ability to analyze circuit problems different from the ones that were practiced in the class, and the ability to design functional circuits using the methods of analyzing non-linear circuits learned in the class. To achieve these learning outcomes, students needed to reach a higher level of learning and mastery in analyzing the related circuits.

To this end, the researcher designed a series of multiple choice and iClicker questions for each lecture in the Winter quarter of 2018. Peer instruction was an integral part of the redesign and one of the primary modalities for meeting the mastery learning outcome. The researcher could see the efficacy of providing time in class for students to solve problems and work together; however, these active learning strategies took time. To address this issue, a blended model of instruction was built into the design of the course in the Spring quarter. Students had the choice to view pre-recorded lectures of the material that would have been traditionally covered in class. In addition, to support their learning, optional take-home tests were offered that were designed to facilitate mastery of the material.

Peer instruction and pre-lecture videos

In integrating the peer instruction and pre-lecture videos into the course, the researcher considered the educational research on the benefits of flipping the instruction which allowed 
students the opportunity for an appropriate amount of time to work individually on the multiplechoice questions (Dolan \& Collins, 2015). Furthermore, the instructor's experience in implementing the peer instruction in the Winter quarter contributed to her decision of adding the pre-lecture videos as a new component to the course offered in Spring. In the Winter quarter, while the students had access to the reference notes prior to coming to the class and were encouraged to read the notes in advance and come to the class prepared, most of them did not follow the instructions. As a result, an average student usually did not finish solving the iClicker and discussion questions in the allocated time and couldn't effectively participate in the discussions. The addition of pre-lecture lecture videos to the course in the Spring quarter provided a tool for encouraging students to review lecture content and start the learning process before coming to the class. This, in turn, offered extra time in the class to be spent on peer instruction.

The researcher found that the pre-lecture videos and peer instruction supported student engagement in the in-class activities and noticed observable changes in student behavior. More specifically, the majority of students in the Spring quarter came to class prepared, and usually, the first few minutes of every lecture was spent on answering students' questions about the topics of that lecture. During the lecture, once students had engaged with the multiple choice and discussion questions, they were provided the opportunity to share with their peers their findings, questions, and tumult. This process allowed the instructor and the four teaching assistants who attended the lectures to ask probing questions, check for understanding, and address misconceptions in real time. At the end of the peer review, the instructor solved the problem and explained the solution to the entire class.

The students in the Spring quarter appeared to appreciate the pre-lecture videos and how these videos enhanced the in-class activities. In the mid-quarter survey, in response to the question "what contributes to student learning in this class" fifty percent of the participants cited the prelecture videos, and in the end-of-the-quarter survey, $76 \%$ of the participants agreed or strongly agreed that the pre-lecture videos were helpful to their learning. This is supported in the findings that indicate that students who accessed the pre-lecture video had a positive effect of $8 \%$ on the final exam grade. Regarding students' perception of the effectiveness of peer instruction and discussion or clicker questions, in the mid-quarter survey, $69 \%$ of the participants cited the iClicker and discussion questions as a contributing factor to their learning, and in the end-of-thequarter survey, $72 \%$ of the participants agreed or strongly agreed that the peer instruction and inclass questions were helpful to their learning.

In the written feedback section of the end-of-the-quarter survey, some students mentioned that they would have preferred that all of the lecture content was recorded in the video format and the entire class time would have been spent on solving the iClicker and discussion problems. To further examine this suggestion, the instructor in collaboration with the Teaching and Learning Center at the University prepared a focus group consisting of students who had the experience of taking a fully flipped classroom in the Electrical and Computer Engineering department and some of the students who took Components and Circuits Lab in the Spring and Winter quarters. The results of the focus group indicated that students preferred the flipped classroom method. The instructor aims to offer the course with the flipped method in the future quarters. 
What became clear after reading the survey results and conducting an analysis of the midterm and final exam grades were that students in the Winter quarter were lacking the skills needed to answer the synthesis level problems. In the mid-quarter survey of the Winter quarter, $65 \%$ of the participants mentioned that to be able to solve a problem on the exam, they should have seen a similar one before. This was consistent with how students solved the exam problems that were similar to the homework assignments or the in-class iClicker and discussion questions, but mostly failed to answer the unique problems.

In the Spring quarter, to support the mastery learning outcome, optional take-home tests were offered to all participants. These tests were composed of challenging problems that required students to connect different concepts and draw conclusions. Students were encouraged to work in groups with their peers and ask questions from their teaching assistants or instructor. Since these take-home tests and their implementation method were new to the students in the Electrical and Computer Engineering department, the tests were offered as optional.

Since the test problems were completely new in terms of their similarity to the in-class iClicker and discussion problems, working on these tests helped students improve their confidence, in addition to achieving a mastery level of learning. As the quarter progressed, there was a noticeable increase in confidence when the instructor and teaching assistants were interacting with students as part of the peer review process. For example, the questions posed by students were mostly about their approach to solving the problems and their thought process, which reflected high order thinking about the concepts. This was in contrast with questions like "is option A the correct answer?" usually asked at the beginning of the quarter.

This observed behavioral change is reflected in the analysis of students' perceptions of critical thinking and the results of the final exams. Figure 2 shows the results of mid-quarter and the endof-the-quarter survey question "to what extent do you agree or disagree that you can solve a circuit problem if you have not seen a similar one before?". As shown in the graph, the percentage of students who had a positive response to this question increased at the end of the quarter and the percentage of negative responses decreased. Moreover, in the end-of-the-quarter survey, $86 \%$ of the participants indicated that the take-home tests were effective in helping them practice and learn the course topics. Also, as indicated in Figure 1, the 70 students who did participate in the take-home tests scored 15 percentage points higher on the final exam than the grades of the 11 students who did not choose that option.

Table 7 presents the average GPAs for students who opted into both activities, one activity, or neither activity. While the average GPA of students who completed the optional activities was higher than that of the other groups, there was representation of above-average and belowaverage students within each of the groups. 
To what extent do you agree or disagree with the following statement? I think I can solve a circuit problem if I have not seen a similar one before.

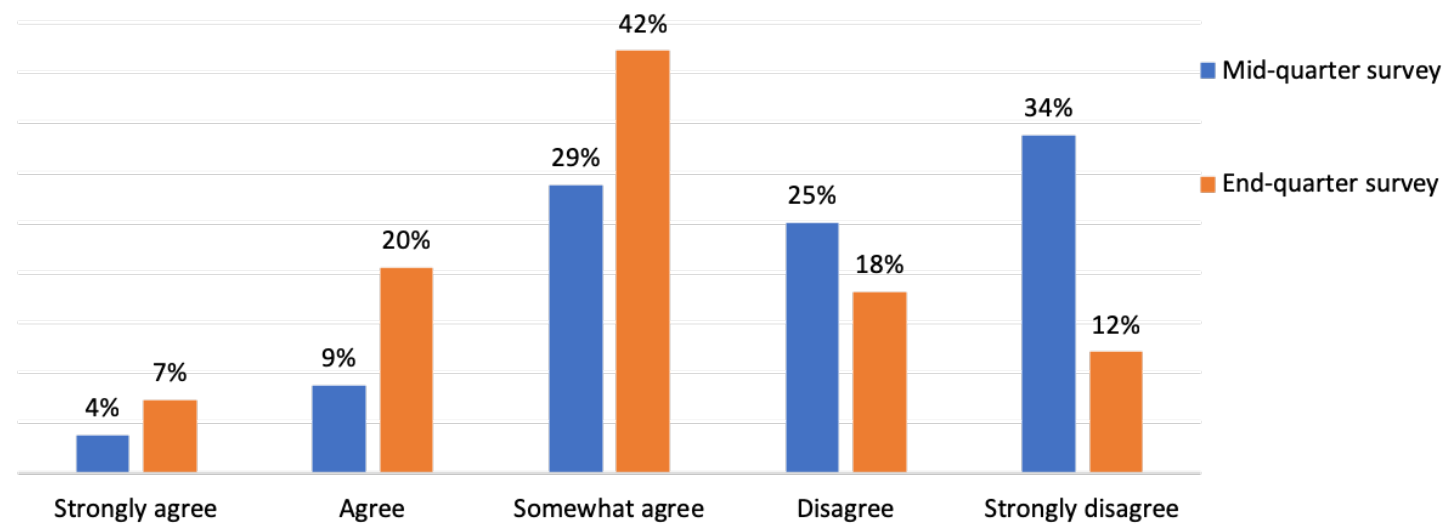

Figure 2. The results of the critical thinking question in the mid-quarter and end-of-the-quarter surveys in Spring 2018.

A challenge that students initially encountered with the take-home tests was with preparing the screencast of their explanations. A few of the students reported that they spent a lot of time editing the videos after recording them. After receiving this feedback, the instructor asked the students not to edit the videos, and add a clarification note to their report if they made a mistake in their explanation.

Replacing Homework assignments with Weekly Quizzes

In the Spring quarter, the homework assignments previously used in the Winter quarter were replaced with the weekly quizzes. Each quiz consisted of two circuit problems designed in the format of multiple-choice questions and they were assigned to students on a weekly basis through the Learning Management System (LMS). All of the problems in the weekly quizzes had instructions on how to solve them. Students were encouraged to work on the weekly quiz problems with their peers; however, to earn credit, each student had to submit their responses individually through their accounts. The problems in these quizzes were similar to the homework problems in the Winter quarter.

Among the reasons for replacing the homework assignments with weekly quizzes, the most important one was the positive student feedback that the instructor received after using similar guided quizzes in a different course. The routine schedule of assigning these quizzes on Friday of every week was also intended to urge the students to review the topics of the week at the end of the week and to help them with developing good study habits. Furthermore, since the quizzes were graded by LMS, the teaching assistants could attend the lecture classes and participate in the in-class discussions instead of grading the homework assignments.

Students' perceptions of the effectiveness of the weekly quizzes in helping them learn the course topics are assessed in the end-of-the-quarter survey. According to the survey results, $63 \%$ of the students rated these quizzes as somewhat effective and $13 \%$ as very effective. 
Although the instructor did not observe any issues with these quizzes, a potential problem could be that the student might get overwhelmed with both the weekly quizzes and the quizzes at the end of the pre-lecture videos. Nevertheless, because these are optional and there are no high stakes points assigned to students' grades, they may be more inclined to attempt to complete them.

\section{Conclusion}

The new components, peer instruction, pre-lecture videos, and take-home tests, added to Components and Circuits Lab over the Winter and Spring quarters in 2018 proved to have a positive impact on students' ability to solve unique and complex circuit problems, and in helping them achieve a higher level of learning the course topics. These techniques are not limited to the circuits classes and can be implemented in a vast range of engineering and non-engineering courses. The researcher will collaborate with the instructors of the IoT (Internet of Things) course at UC San Diego to integrate these techniques into their course.

In the future, the instructor intends to pre-record all the course topics and spend the entire class time on peer instruction and solving iClicker and discussion questions. In addition, due to the successful results with the take-home tests and to increase student engagement with the course materials, the instructor will increase the number of take-home tests to three such that students would take one test before their midterm exam and the other two tests between the midterm and final exams.

\section{Acknowledgment}

The researcher acknowledges the assistance, mentoring and reflection on teaching sessions offered by the Center for Teaching and Learning at UC San Diego.

\section{References}

Ahern, A., O'Connor, T., McRuairc, G., McNamara, M., \& O’Donnell, D. (2012). Critical thinking in the university curriculum - The impact on engineering education. Journal of Engineering Education 37(2), 125-132.

Baghdadchi, S., Hardesty, R., Hadjipieris, P. A., \& Hargis, J. (2018). Active Techniques Implemented in an Introductory Signal Processing Course to Help Students Achieve Higher Levels of Learning. American Society for Engineering Education.

Bordogna, J., Fromm, E., \& Ernst, E. W. (1993). Engineering education: Innovation through integration. Journal of Engineering Education. 82(1), 3-8.

Claris, L., \& Riley, D. (2012). Situation critical: Critical theory and critical thinking in engineering education. Engineering Studies 4(2), 101-120. 
Clark, R., Autar, K., Yingyan, L., Scott, A., \& Besterfield-Sacre, M. (2018). Evaluating blended and flipped instruction in numerical methods at multiple engineering schools. International Journal for the Scholarship of Teaching and Learning 12(1).

Dziuban, C., \& Moskal, P. (2011). A course is a course is a course: Factor invariance in student evaluation of online, blended and face-to-face learning environments. The Internet and Higher Education, 14(4), 236-241.

Ennis, R. H. (1985). A logical basis for measuring critical thinking skills. Educational leadership, 43(2), 44-48.

Felder, R. M., Woods, D. R., Stice, J. E., \& Rugarcia, A. (2000). The future of engineering education II. Teaching methods that work. Chemical Engineering Education, 34(1), 26-39.

Freeman, S., Eddy, S. L., McDonough, M., Smith, M. K., Okoroafor, N., Jordt, H., \& Wenderoth, M. P. (2014). Active learning increases student performance in science, engineering, and mathematics. Proceedings of the National Academy of Sciences.

Jensen, J. L., Kummer, T. A., \& Godoy, P. D. D. M. (2015). Improvements from a flipped classroom may simply be the fruits of active learning. CBE_Life Sciences Education, 14(1), $\operatorname{ar} 5$.

Mills, J. E., \& Treagust, D. F. (2003). Engineering education - Is problem-based or project-based learning the answer? Australasian Journal of Engineering Education. 3 http://www.aaee.com.au/journal/2003/mills_treagust03.pdf

Nicol, D. (2007). E-assessment by design: Using multiple-choice tests to good effect. Journal of Further and Higher Education 31(1), 53-64.

Perrenet, J. C., Bouhuijs, P. A. J., \& Smits, J. G. M. M. (2000). The suitability of problem-based learning for engineering education: Theory and practice. Teaching in Higher Education 5(3), 345-358.

Prince, M. (2004). Does active learning work? A review of the research. Journal of engineering education 93(3), 223-231.

Siegel, H. (1980). Critical thinking as an educational ideal. The Educational Forum. Taylor \& Francis Group. 45(1), 7-23

Singer, S., \& Smith, K. A. (2013). Discipline-based education research: Understanding and improving learning in undergraduate science and engineering. Journal of Engineering Education $102(4), 468-471$.

Siller, T. J. (2001). Sustainability and critical thinking in civil engineering curriculum. Journal of Professional Issues in Engineering Education and Practice 127(3), 104-108. 
Springer, L., Stanne, M. E., \& Donovan, S. S. (1999). Effects of small-group learning on undergraduates in science, mathematics, engineering, and technology: A meta-analysis. Review of educational research, 69(1), 21-51.

Tsui, L. (2002). Fostering critical thinking through effective pedagogy. Journal of Higher Education 73(6), 740-763.

Wiggins, G., Wiggins, G. P., \& McTighe, J. (2005). Understanding by design. Ascd.

Wold, K. (2013). Collaborative inquiry: Expert analysis of blended learning in higher education. International Journal on E-learning, 12(2), 221-238.

Woods, D. R., Felder, R. M., Rugarcia, A., \& Stice, J. E. (2000). The future of engineering education. Chemistry Engineering Education, 34(2), 108-117 